\title{
Reducing Persistent Postoperative Pain and Disability 1 Year After Breast Cancer Surgery: A Randomized, Controlled Trial Comparing Thoracic Paravertebral Block to Local Anesthetic Infiltration
}

\author{
Michelle Chiu, MD, FRCPC ${ }^{1,4}$, Gregory L. Bryson, MD, FRCPC, MSc ${ }^{1,4}$, Anne Lui, MD, MSc, FRCPC ${ }^{1,4}$, \\ James M. Watters, MD, FRCSC ${ }^{2,4}$, Monica Taljaard, PhD $^{3}$, and Howard J. Nathan, MD, FRCPC ${ }^{1,4}$ \\ ${ }^{1}$ Department of Anesthesiology, University of Ottawa, Ottawa, ON, Canada; ${ }^{2}$ Department of Surgery, University of \\ Ottawa, Ottawa, ON, Canada; ${ }^{3}$ Clinical Epidemiology Program, Department of Epidemiology and Community Medicine, \\ Ottawa Hospital Research Institute, University of Ottawa, Ottawa, ON, Canada; ${ }^{4}$ The Ottawa Hospital, Ottawa, ON, \\ Canada
}

\begin{abstract}
Background. The objective of this study was to compare the effect of thoracic paravertebral block (TPVB) and local anesthetic (LA) on persistent postoperative pain (PPP) 1 year following breast cancer surgery. Secondary objectives were to compare the effect on arm morbidity and quality of life.

Methods. Women scheduled for elective breast cancer surgery were randomly assigned to either TPVB or LA followed by general anesthesia. An NRS value of $>3$ at rest or with movement 1 year following surgery defined PPP. Blinded interim analysis suggested rates of PPP much lower than anticipated, making detection of the specified $20 \%$ absolute reduction in the primary outcome impossible. Recruitment was stopped, and all enrolled patients were followed to 1 year.

Results. A total of 145 participants were recruited; 65 were randomized to TPVB and 64 to LA. Groups were similar with respect to demographic and treatment characteristics. Only 9 patients (8\%; $95 \%$ CI 4-14\%) met criteria for PPP 1 year following surgery; 5 were in the TPVB and 4 in the LA group. Brief Pain Inventory severity and interference scores were low in both groups. Arm morbidity and quality of life were similar in both groups.
\end{abstract}

(C) The Author(s) 2013. This article is published with open access at Springerlink.com

First Received: 25 June 2013;

Published Online: 29 October 2013

M. Chiu, MD, FRCPC

e-mail: mchiu@toh.on.ca
The 9 patients with PPP reported shoulder-arm morbidity and reduced quality of life.

Conclusions. This study reports a low incidence of chronic pain 1 year following major breast cancer surgery. Although PPP was uncommon at 1 year, it had a large impact on the affected patients' arm morbidity and quality of life.

Breast cancer is the most common cancer among adult women. ${ }^{1}$ Pain in the ipsilateral arm and shoulder persisting 6 months or more after surgical treatment has been reported in $25-60 \%$ of women. ${ }^{2-5}$ The etiology of this pain is multifactorial: The intercostobrachial nerve may be damaged in $80-100 \%$ of patients undergoing axillary lymph node dissection (ALND), phantom and neuropathic pain may result from injury to nerves that supply the breast and axilla, and neuromas may form in scar tissue. ${ }^{2-4}$ Persistent postoperative pain (PPP) causes both psychological distress and disability in those affected. ${ }^{6,7}$ Reduced range of motion of the shoulder, muscle weakness, and lymphedema are also commonly reported. ${ }^{6-8}$

Multimodal analgesia strategies may reduce the incidence of PPP. ${ }^{4,9}$ Thoracic paravertebral nerve block (TPVB) and infiltration of local anesthetics (LA) at the surgical site are 2 techniques shown to independently reduce both short-term and long-term pain following breast surgery. ${ }^{9-12}$ The comparative impact of these techniques on PPP, arm morbidity, functional recovery, and quality of life has not been explored.

The objective of this study was to compare the effect of TPVB and LA on PPP 1 year following breast cancer 
surgery. We hypothesized that fewer women receiving TPVB would report numeric pain scores $>31$ year following surgery than those receiving LA. Secondary objectives of this study were to determine the effect of TPVB and LA on arm morbidity and quality of life at 1 year.

\section{METHODS}

This randomized, controlled, double-blinded trial was registered on ClinicalTrials.gov (NCT01089933) and approved by The Ottawa Hospital Research Ethics Board (Protocol 2006711-01H). It was conducted at The Ottawa Hospital, a 900-bed, tertiary care academic health science center affiliated with the University of Ottawa.

\section{Population}

Women $>18$ years of age with breast cancer scheduled for elective breast conserving surgery with ALND, simple mastectomy with sentinel lymph node biopsy (SLNB), modified radical mastectomy (MRM), or ALND alone were evaluated by research personnel for participation. Exclusion criteria included ASA class 4 or 5, allergy to study medications, contraindications to TPVB, consumption of $>20 \mathrm{mg}$ of oral morphine or equivalent for $>7$ days, creatinine clearance $<40 \mathrm{ml} /$ minute (calculated using the Cockroft-Gault formula), preoperative radiation therapy or $<100^{\circ}$ of shoulder abduction or flexion.

\section{Randomization and Allocation Concealment}

Eligible, consenting participants were allocated in parallel to TPVB and LA groups in a 1:1 ratio using computergenerated random numbers. Randomization was blocked in groups of 4-8 and stratified according to type of surgery. Allocation to TPVB or LA group was printed on cards placed in sealed, opaque, sequentially numbered envelopes. Envelopes were opened immediately before surgery by the attending anesthesiologist who prepared study medications. Patients, surgeons, and study personnel remained blinded to group allocation.

\section{Preoperative Management}

All patients received oral celecoxib $400 \mathrm{mg}$ and acetaminophen $650 \mathrm{mg} 2 \mathrm{~h}$ preoperatively. Participants allocated to the TPVB group received nerve blocks at the T1-T6 levels; $5 \mathrm{~mL}$ of $0.5 \%$ ropivacaine with epinephrine was injected at each space. ${ }^{13}$ Those allocated to the LA group received subcutaneous injections of $0.9 \% \mathrm{NaCl}$ at each level.

\section{Intraoperative Management}

A standardized general anesthetic using propofol, fentanyl, dexamethasone, and volatile anesthetic gas was given. At the conclusion of surgery, the surgeon infiltrated the wound edges with $10 \mathrm{~mL}$ of study solution: $0.9 \%$ $\mathrm{NaCl}$ in the TPVB group or $0.5 \%$ ropivacaine with epinephrine in the LA group. After closure of the wound, a further $20 \mathrm{ml}$ of study solution was instilled through the surgical drain, which was then clamped for $30 \mathrm{~min}$.

\section{Postoperative Management}

Following discharge from hospital, patients received oral acetaminophen $650 \mathrm{mg}$ every $4 \mathrm{~h}$ for $48 \mathrm{~h}$ and celecoxib $200 \mathrm{mg}$ every $12 \mathrm{~h}$ for 7 days in addition to their standardized hydromorphone opioid prescription.

\section{Outcome Assessments}

All measures were compliant with the Initiative on Methods, Measurement, and Pain Assessment in Clinical Trials (IMMPACT) and were performed before and 1 year after surgery. ${ }^{14}$ Assessments were scheduled to not coincide with chemotherapy or radiation therapy.

Primary Outcome Pain was assessed using an 11-point numeric rating scale (NRS) with 0 representing "no pain" and 10 representing "pain as bad as you can imagine." An NRS value of $>3$ at rest or with movement 1 year following surgery defined PPP.

Secondary Outcomes The Brief Pain Inventory (BPI) quantified the intensity of pain using four 11-point NRS scores that defined current, worst, least, and average pain scores over the preceding $24 \mathrm{~h}^{15}$ The BPI also assessed the degree to which pain interferes with 7 daily activities using 11-point NRS scores anchored at 0 "does not interfere" and 10 "interferes completely." Patients found to have PPP were referred to the Ottawa Regional Cancer Centre Pain and Symptom Management Clinic.

Flexion, extension, abduction, internal, and external rotation of the shoulder was assessed in both shoulders with a fixed scapula using a 12-in. universal goniometer. Relative shoulder movement, defined as ipsilateral movement/ contralateral movement $\times 100$, was assessed. A value of $<90 \%$ was taken to indicate functional impairment. ${ }^{16}$ Measurements of arm circumference were made across the metacarpal joint at the hand, at the radial styloid and every $10 \mathrm{~cm}$ proximal to that point. Relative arm circumference was defined as ipsilateral circumference/contralateral circumference $\times 100$. A value of $>110 \%$ was taken to indicate the presence of lymphedema. ${ }^{6}$ The Constant score 
quantifies overall disability of the arm and shoulder by combining assessments of pain, activities of daily living, range of motion, and power in a single metric with a maximum score of $100 .{ }^{17}$ This score has been used in breast cancer research and has well-defined reliability and validity. ${ }^{18,19}$ Quality of life was assessed using the FACTB+4 and the SF-12 Health Survey (SF12). ${ }^{20,21}$ The FACT$\mathrm{B}+4$ is a comprehensive, breast cancer specific questionnaire that incorporates 5 domains (concerns specific to patients with breast cancer, and physical, social, emotional, and functional well-being). The SF12 is a well-validated, generic, measure of quality of life. Details of the surgery, chemotherapy, and/or radiation therapy were recorded.

\section{Sample Size Estimate}

Previous research demonstrated that $\sim 25-60 \%$ of patients have pain 1 year following breast cancer surgery. $^{2-5}$ We took a midrange estimate of $40 \%$ and considered a $20 \%$ absolute reduction in the prevalence of pain as clinically important. Using a 2-sided test at the $5 \%$ level of significance, a sample of 82 patients per group would yield $80 \%$ power to detect a difference of this magnitude. Anticipating a $10 \%$ drop-out rate, we proposed a final sample size of 91 per group.

\section{Interim Analysis}

In July 2011 the Data Safety Monitoring Board performed an interim analysis of blinded, aggregate data. No safety issues were identified among the 66 participants enrolled to this point; however, only 7 participants (11\%, $95 \%$ exact confidence limits 4.4-20.6\%) reported PPP 1 year following surgery. Detection of the specified $20 \%$ absolute reduction in the primary outcome was therefore impossible. Thus, recruitment was stopped, and all enrolled patients were followed to 1 year to provide an estimate of the primary outcome and permit an exploration of secondary outcomes.

\section{Statistics}

Demographic characteristics were summarized for the treatment and control group using means and standard deviations for continuous measures (or medians and interquartile ranges in the case of skewed distributions) and frequencies and proportions for categorical measures. The primary outcome (proportion of patients with arm pain NRS $>3$ at rest or with arm movement at 1 year) was analyzed using Fisher exact test. Continuous secondary outcomes were assessed for normality and compared at 1 year using 2-sample $t$ tests or 2-sample Wilcoxon tests, while categorical outcomes were assessed using Pearson
Chi squared tests. SAS v 9.2 was used for all analyses. A 2sided $5 \%$ level of significance was used for all statistical tests.

\section{RESULTS}

Trial recruitment began December 6, 2007 with the last measurement concluded September 28, 2012, A total of 145 participants were recruited; of these, 65 were randomized to the TPVB group and 64 to the LA group. Participant flow is documented in a CONSORT diagram (Fig. 1).

The groups were similar with respect to demographic and treatment characteristics (Table 1). The majority of patients in both groups underwent MRM or simple mastectomy with SNLB (Table 2). There were no surgical complications that required reoperation. The majority of patients in both groups received postoperative chemotherapy and radiation therapy. The dosing and distribution of radiation therapy and number of treatments were similar between groups.

Chronic pain, arm disability, and quality of life data are shown in Table 3 . Only 9 patients (8\%; $95 \%$ CI 4-14\%) met criteria for PPP 1 year following surgery; 5 in the TPVB group and 4 patients in the LA group. Since the trial was not powered to detect differences in these outcomes,

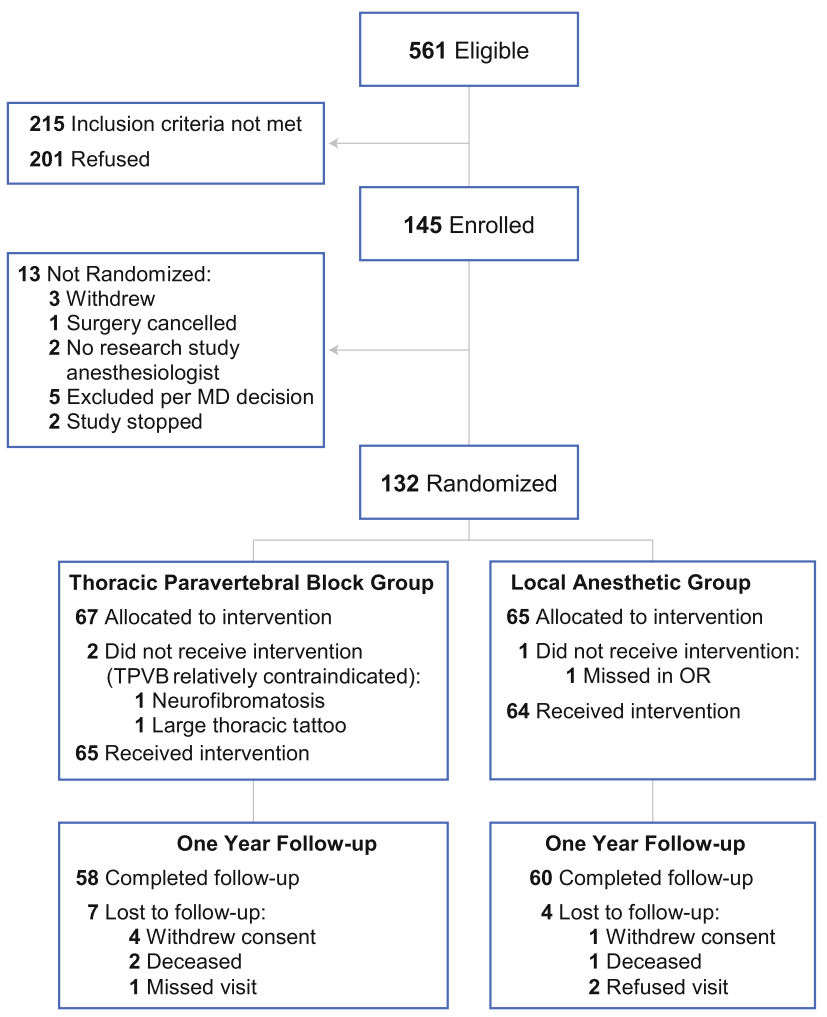

FIG. 1 CONSORT diagram showing patient eligibility, enrollment, randomization, and follow-up 
TABLE 1 Preoperative patient characteristics (mean, SD)

\begin{tabular}{|c|c|c|}
\hline Characteristic & TPVB $(N=65)$ & LA $(N=64)$ \\
\hline Age & $54(10.8)$ & $56(10.6)$ \\
\hline BMI & $28.4(6.5)$ & $29.0(5.2)$ \\
\hline \multicolumn{3}{|l|}{ ASA } \\
\hline 1 & $11(17 \%)$ & $3(5 \%)$ \\
\hline 2 & $36(55 \%)$ & $42(65 \%)$ \\
\hline 3 & $18(28 \%)$ & $19(30 \%)$ \\
\hline Neoadjuvant hormonal therapy & $4(6 \%)$ & $4(6 \%)$ \\
\hline Neoadjuvant chemotherapy & $14(22 \%)$ & $10(16 \%)$ \\
\hline Medical comorbidities & $31(48 \%)$ & $23(36 \%)$ \\
\hline Fibromyalgia & $2(3 \%)$ & $0(0 \%)$ \\
\hline Anxiety disorder & $3(5 \%)$ & $2(3 \%)$ \\
\hline Depression & $2(3 \%)$ & $3(5 \%)$ \\
\hline Diabetes mellitus & $7(11 \%)$ & $8(13 \%)$ \\
\hline Hypertension & $21(32 \%)$ & $20(31 \%)$ \\
\hline Peripheral vascular disease & $1(2 \%)$ & $0(0 \%)$ \\
\hline Hypercholesterolemia & $7(11 \%)$ & $5(8 \%)$ \\
\hline Stroke/TIA & $0(0 \%)$ & $0(0 \%)$ \\
\hline Small vessel vasculitis & $1(2 \%)$ & $0(0 \%)$ \\
\hline Smoker & $8(13 \%)$ & $7(12 \%)$ \\
\hline \multicolumn{3}{|l|}{ Constant score } \\
\hline Ipsilateral arm & $85.47(9.18)$ & $87.70(7.37)$ \\
\hline Contralateral arm & $87.60(8.28)$ & $88.87(6.02)$ \\
\hline SF-12 MCS & $45.62(11.16)$ & $47.74(9.69)$ \\
\hline SF-12 PCS & $52.54(10.76)$ & $51.60(8.57)$ \\
\hline
\end{tabular}

$B M I$ body mass index, ASA American Society of Anesthesiologist, TIA transient ischemic attack

we focused on clinically important rather than statistically significant differences between groups. Median BPI severity and interference scores were low in both groups. Both groups showed a small decline in Constant scores. There were 6 patients in the TPVB group and 15 in the LA group who had a $10 \%$ relative increase in arm circumference on the side of surgery, suggesting an overall $18 \%$ incidence of lymphedema. Although the absolute difference between groups was $15 \%$ and statistically significant, this result should be interpreted with caution: (1) multiple testing increases the risk of spurious statistical significance, and (2) the confidence interval around the difference is relatively wide (95\% CI 1.2-28.1\%). Shoulder range of motion (ROM), FACT-B+4, and SF-12 Mental (MCS) and Physical (PCS) Component scores were comparable in both groups.

Characteristics of the 9 patients with chronic pain at 1 year are shown in Table 4. These patients had a median of 14 (IQR, 7.0-19.0) lymph nodes removed, and 3 patients (33\%) had their intercostobrachial nerve preserved. Lymphedema was common as was a large decrease in the Constant score in the ipsilateral arm. Lowered quality of
TABLE 2 Patient surgical and postoperative treatment variables (median, IQR) and (mean, SD)

\begin{tabular}{|c|c|c|c|}
\hline & \multicolumn{2}{|c|}{ Treatment variable } & \multirow{2}{*}{$\begin{array}{l}P \\
\text { value }\end{array}$} \\
\hline & $\begin{array}{l}\text { TPVB } \\
(N=65)\end{array}$ & $\begin{array}{l}\mathrm{LA} \\
(N=64)\end{array}$ & \\
\hline \multicolumn{4}{|l|}{ Surgical variables } \\
\hline Procedure & & & 0.257 \\
\hline $\begin{array}{l}\text { Breast conserving } \\
\text { surgery }+ \text { ALND }\end{array}$ & $9(14 \%)$ & $6(9 \%)$ & \\
\hline $\begin{array}{l}\text { MRM or Simple } \\
\text { mastectomy }+ \text { SLNB }\end{array}$ & $54(83 \%)$ & $58(91 \%)$ & \\
\hline ALND alone & $2(3 \%)$ & $0(0 \%)$ & \\
\hline $\begin{array}{l}\text { Number lymph nodes } \\
\text { removed }\end{array}$ & $7(3,13)$ & $9.5(4.5,19)$ & 0.040 \\
\hline $\begin{array}{l}\text { Intercostobrachial } \\
\text { nerve preserved }\end{array}$ & $43(73 \%)$ & $27(50 \%)$ & 0.012 \\
\hline \multicolumn{4}{|l|}{ Medical oncology variables } \\
\hline $\begin{array}{l}\text { Adjuvant chemotherapy } \\
\text { received }\end{array}$ & $41(63 \%)$ & $37(58 \%)$ & 0.507 \\
\hline \multicolumn{4}{|l|}{ Radiation oncology variables } \\
\hline $\begin{array}{l}\text { Radiation therapy } \\
\text { received }\end{array}$ & $37(57 \%)$ & $42(66 \%)$ & 0.310 \\
\hline Total dose & $48.1(2.90)$ & $49.0(2.00)$ & 0.193 \\
\hline Total dose per fraction & $2.09(0.20)$ & $2.04(0.11)$ & 0.192 \\
\hline \multicolumn{4}{|l|}{ Site of radiation } \\
\hline Breast or chest wall & $37(57 \%)$ & $42(66 \%)$ & 0.310 \\
\hline $\begin{array}{l}\text { Breast or chest wall }+ \\
\text { lymph nodes }\end{array}$ & $31(48 \%)$ & $38(59 \%)$ & 0.184 \\
\hline
\end{tabular}

$A L N D$ axillary lymph node dissection, $S L N B$ sentinel lymph node biopsy, $M R M$ modified radical mastectomy

life was reflected in FACT-B +4 and SF-12 PCS scores. Despite pain and swelling, ROM of both arms was preserved and no patient required opioid analgesia.

\section{DISCUSSION}

\section{Incidence of Persistent Postoperative Pain}

Only $8 \%$ of women in this trial reported PPP 1 year following major breast cancer surgery; much lower than the $25-60 \%$ reported in the literature. Because of the surprisingly low incidence of PPP, we were unable to compare the efficacy of TPVB and LA. Possible explanations for this discrepancy are: study design, perioperative surgical care, perioperative anesthesia care, and definition of PPP. The majority of studies on PPP following breast surgery are conducted retrospectively via questionnaire, $\sim 2-2.5$ years and up to 3.5-4 years following surgery. ${ }^{5,22-25}$ The retrospective questionnaire study design and long duration since the inciting event, increase the possibility of error. In contrast, patients in our study were 
TABLE 3 Summary of primary and secondary outcomes by groups at 1 year (median, IQR) and (mean, SD)

\begin{tabular}{|c|c|c|c|}
\hline Assessment tool & $\operatorname{TPVB}(N=58)$ & $\mathrm{LA}(N=60)$ & $\begin{array}{l}P \\
\text { value }\end{array}$ \\
\hline \multicolumn{4}{|l|}{ Primary outcome } \\
\hline Chronic pain & $5(9 \%)$ & $4(7 \%)$ & 0.741 \\
\hline \multicolumn{4}{|l|}{ Secondary outcome } \\
\hline BPI pain severity & $0.125(0-2.25)$ & $0.25(0-1.50)$ & 0.989 \\
\hline Pain interference & $0(0-1)$ & $0(0-0.86)$ & 0.744 \\
\hline Opioids taken & $1(2 \%)$ & $1(2 \%)$ & 1.000 \\
\hline \multicolumn{4}{|l|}{ Constant score } \\
\hline $\begin{array}{l}\text { Change from } \\
\text { baseline (ipsilateral } \\
\text { arm) }\end{array}$ & $-5.23(15.02)$ & $-7.23(13.53)$ & 0.448 \\
\hline $\begin{array}{l}\text { Change from } \\
\text { baseline } \\
\text { (contralateral arm) }\end{array}$ & $-2.25(13.57)$ & $-3.01(11.60)$ & 0.809 \\
\hline FACT-B $+4^{\mathrm{a}}$ & $\begin{array}{c}138.5(116 \\
148.75)\end{array}$ & $\begin{array}{c}139.5(125.38 \\
151.5)\end{array}$ & 0.683 \\
\hline $\begin{array}{l}\text { SF-12 MCS (change } \\
\text { from baseline) }\end{array}$ & $6.06(9.86)$ & $4.62(9.28)$ & 0.417 \\
\hline $\begin{array}{l}\text { SF-12 PCS (change } \\
\text { from baseline) }\end{array}$ & $-4.66(12.96)$ & $-4.83(9.22)$ & 0.934 \\
\hline Arm lymphedema & $6(10 \%)$ & $15(25 \%)$ & 0.038 \\
\hline \multicolumn{4}{|l|}{$\begin{array}{l}\text { Shoulder range of } \\
\text { motion }\end{array}$} \\
\hline $\begin{array}{l}\text { Ipsilateral arm- } \\
\text { degrees forward }\end{array}$ & $160(150,160)$ & $160(140,160)$ & 0.388 \\
\hline $\begin{array}{l}\text { Ipsilateral arm- } \\
\text { degrees abduction }\end{array}$ & $160(155,160)$ & $160(147.5,160)$ & 0.485 \\
\hline $\begin{array}{c}\text { Contralateral arm- } \\
\text { degrees forward }\end{array}$ & $160(160,160)$ & $160(159.5,160)$ & 0.324 \\
\hline $\begin{array}{c}\text { Contralateral arm- } \\
\text { degrees abduction }\end{array}$ & $160(160,160)$ & $160(154,160)$ & 0.612 \\
\hline
\end{tabular}

SF-12 MCS SF-12 mental component summary, SF-12 PCS SF-12 physical component summary

${ }^{a}$ Only recorded postoperatively

prospectively assessed by a trained nurse at each follow-up visit.

Intercostobrachial neuralgia is a recognized etiology of chronic pain following breast cancer surgery. ${ }^{2}$ It has been recommended that for optimal quality of cancer care, "not only treatment of tumours with a low incidence but also other complex or high risk cancer procedures should be provided in a specialized setting, with the right infrastructure, sufficient volume and adequate expertise." ${ }^{26}$ All surgeons involved in this study have subspecialized practices focusing on breast cancer surgery. Although no studies have been done to directly examine the relationship between surgical expertise and pain outcomes, Kehlet ${ }^{27}$ suggests that "nerve injury might be reduced by surgical expertise," thus reducing the risk of PPP. Indeed in the majority of our patients, the intercostobrachial nerve was identified and preserved. The median number of lymph nodes removed in our study is on the lower end of the range reported by Olaya et al. ${ }^{28}$ who examined the number of nodes removed in current surgical practice. These authors noted that "increased breast surgery practice is associated with a decreased number of (nodes) removed." Since there is a proportional relationship between the number of lymph nodes removed and the occurrence of PPP following breast cancer surgery, the low number of nodes removed is in keeping with our speculation that surgical factors in our study may have contributed toward improved pain outcomes. ${ }^{29}$

The intensity of acute postoperative pain has been identified as a predisposing risk factor to the development of PPP..$^{23,30,31}$ The anesthetic techniques used in this study incorporated multimodal, procedure-specific techniques designed to minimize postoperative pain. Both TPVB and LA infiltration have been shown to provide superior analgesia in breast surgery compared with opioid medications alone. ${ }^{4,9}$ Mitchell et al. ${ }^{32}$ showed that co-analgesics acetaminophen + ibuprofen were as effective as Tylenol 3 in treating pain in breast cancer patients. We preemptively treated and postoperatively prescribed to patients a long (7day) course of co-analgesic medications that have been shown to contribute to improved postoperative analgesia. ${ }^{33}$ The synergism of multimodal pain regimens using TPVB or LA infiltration, in combination with effective co-analgesics and meticulous surgical practices, likely contributed to our low incidence of PPP.

There is no agreement in the literature on the definition of PPP; many studies use subjective definitions. ${ }^{34}$ Grigoras et al. $^{35}$ prospectively studied 36 breast cancer patients receiving perioperative intravenous lidocaine versus placebo and found an overall 3-month incidence of PPP of $31 \%$; however, they subjectively defined PPP as an affirmative answer to "Have you had pain in the last week which you attribute to your breast surgery?". Fabro et al. ${ }^{29}$ reported prospective data collected 6 months following breast cancer surgery and found a $52 \%$ incidence of pain. These investigators also defined pain subjectively using reports of hyperesthesia and percussion tenderness. Neither author used established and validated measurement tools to evaluate for the presence of pain. We used multiple, robust measures of pain intensity in our study and considered it important to use a meaningful definition of PPP that has functional significance to the patient. A NRS $>3$ signifies pain that impacts a patient's mood and activity and is a reliable, well established definition of clinically relevant moderate to severe pain in cancer patients. ${ }^{36-38}$ Our patients' low BPI pain severity scores and low interference scores corroborate our low rate of PPP. ${ }^{37,38}$ 
TABLE 4 Outcomes of patients with persistent postoperative pain (median, IQR) and (mean, SD)

\begin{tabular}{ll}
\hline Assessment tool & $\begin{array}{l}\text { Patients with pain } \\
(N=9)\end{array}$ \\
\hline BPI Pain severity & $3.25(2.75-4.25)$ \\
Pain interference & $4.57(2.14-5.00)$ \\
Constant score & \\
Change score from baseline (ipsilateral & $-24.69(18.01)$ \\
$\quad$ arm) & \\
Change score from baseline (contralateral & $-4.24(17.73)$ \\
$\quad$ arm) & $109.00(92.00,120.00)$ \\
FACT-B+4 & $9.50(10.56)$ \\
SF-12 MCS (change from baseline) & $-17.14(18.34)$ \\
SF-12 PCS (change from baseline) & $6(67 \%)$ \\
Arm lymphedema & \\
Shoulder range of motion & $160(130,160)$ \\
Ipsilateral arm—degrees forward & $160(120,160)$ \\
Ipsilateral arm—degrees abduction & $160(160,160)$ \\
Contralateral arm-degrees forward & $160(160,160)$ \\
Contralateral arm—degrees abduction &
\end{tabular}

\section{Arm Morbidity and Quality of Life}

Patients in our study showed impairments in ROM classified as "mild" when compared with age and gender norms $^{39}$ Our $18 \%$ overall incidence of lymphedema is comparable to that reported in the literature as are our patients' SF-12 and FACT-B+4 scores. ${ }^{40-42}$ It should be noted, however, Constant scores were reduced, lymphedema was more common, and quality of life was poor among the 9 women with PPP. Indeed, their 1-year SF-12 PCS was similar to that reported by patients with chronic heart, lung, and kidney disease and their FACT-B+4 scores were lower than those reported in the ALMANAC study, indicating a severe, disease-specific burden of illness. ${ }^{42,43}$ Clearly PPP is a significant problem for those affected.

\section{Study Limitations}

Our study was stopped early following interim analysis. Expanding to a multicenter study may have allowed for increased patient recruitment. Because of our low incidence of PPP, we had insufficient events to allow for identification of predictors for PPP.

\section{CONCLUSIONS}

This prospective study reports an $8 \%$ incidence of PPP 1 year following major breast cancer surgery with lymph node resection. Our patients experienced minor declines in arm function, and quality of life did not diminish. Patients can be reassured that experienced surgical teams dedicated to breast oncology who use multimodal analgesic therapies may achieve low rates of PPP and preserve both activity and quality of life 1-year following breast surgery. Although PPP was not frequent at 1 year, it did have a large impact on the affected patients' arm morbidity and quality of life. Future avenues of research should continue to focus on ways to reduce and treat PPP and arm morbidity in women undergoing breast cancer surgery.

ACKNOWLEDGMENT Funded by Grants from the Canadian Breast Cancer Foundation, Ottawa Regional Cancer Centre, The Ottawa Hospital Women's Breast Health Centre, and Canadian Anesthesia Research Foundation. We thank our surgeons: Drs. Angel Arnaout, Christopher Chadwick, John Lorimer, and Dennis Pitt, who provided and cared for study patients; our anesthesiologists: Drs. Holly Evans, John Hooper, Alan Lane, Peter MacEwen, and Desiree Persaud, who provided anesthetic care for study patients; our oncologists: Drs. Peter Cross and Roanne Segal for critically reviewing the study protocol and assisting with data interpretation; Denise Wozny for data management and Tinghua Zhang for statistical analysis; and the Department of Anesthesiology research team for their support of this project. Drs. Chiu and Bryson were supported by The Ottawa Hospital Anesthesia Alternate Funds Association.

CONFLICTS OF INTEREST The authors have no conflicts of interest in the subject of study.

OPEN ACCESS This article is distributed under the terms of the Creative Commons Attribution License which permits any use, distribution, and reproduction in any medium, provided the original author(s) and the source are credited.

\section{REFERENCES}

1. Canadian Cancer Society's Steering Committee on Cancer Statistics. Canadian Cancer Statistics 2012. Toronto, ON: Canadian Cancer Society, 2012.

2. Wallace MS, Wallace AM, Lee J, Dobke MK. Pain after breast surgery: a survey of 282 women. Pain. 1996;66:195-205.

3. Jung BF, Ahrendt GM, Oaklander AL, Dworkin RH. Neuropathic pain following breast cancer surgery: proposed classification and research update. Pain. 2003;104:1-13.

4. Kairaluoma PM, Bachmann MS, Rosenberg PH, Pere PJ. Preincisional paravertebral block reduces the prevalence of chronic pain after breast surgery. Anesth Analg. 2006;103:7038.

5. Steegers MA, Wolters B, Evers AW, Strobbe L, Wolder-Smith $\mathrm{OH}$. Effect of axillary lymph node dissection on prevalence and intensity of chronic and phantom pain after breast cancer surgery. J Pain. 2008;9:813-22.

6. Rietman JS, Dijkstra PU, Hoekstra HJ, Eisma WH, Szabo BG, Groothoff JW, et al. Late morbidity after treatment of breast cancer in relation to daily activities and quality of life: a systematic review. Eur J Surg Oncol. 2003;29:229-38.

7. Hack TF, Cohen L, Katz J, Robson LS, Goss P. Physical and psychological morbidity after axillary lymph node dissection for breast cancer. J Clin Oncol. 1999;17:143-9.

8. Clark B, Sitzia J, Harlow W. Incidence and risk of arm oedema following treatment for breast cancer: a three-year follow-up study. QJM. 2005;98:343-8. 
9. Fassoulaki A, Triga A, Melemeni A, Sarantopoulos C. Multimodal analgesia with gabapentin and local anesthetics prevents acute and chronic pain after breast surgery for cancer. Anesth Analg. 2005;101:1427-32.

10. Coveney E, Weltz CR, Greengrass R, Iglehart JD, Leight GS, Steele SM, et al. Use of paravertebral block anesthesia in the surgical management of breast cancer: experience in 156 cases. Ann Surg. 1998;227:496-501.

11. Weltz CR, Greengrass RA, Lyerly HK. Ambulatory surgical management of breast carcinoma using paravertebral block. Ann Surg. 1995;222:19-26.

12. Fassoulaki A, Sarantopoulos C, Melemeni A, Hogan Q. EMLA reduces acute and chronic pain after breast surgery for cancer. Reg Anesth Pain Med. 2000;25:350-5.

13. Klein SM, Bergh A, Steele SM, Georgiade GS, Greengrass RA. Thoracic paravertebral block for breast surgery. Anesth Analg. 2000;90:1402-5.

14. Dworkin RH, Turk DC, Farrar JT, Haythornthwaite JA, Jensen MP, Katz NP, et al. Core outcome measures for chronic pain clinical trials: IMMPACT recommendations. Pain. 2005;113:919.

15. Tan G, Jensen MP, Thornby JI, Shanti BF. Validation of the brief pain inventory for chronic nonmalignant pain. J Pain. 2004;5: 133-7.

16. Sugden EM, Rezvani M, Harrison JM, Hughes LK. Shoulder movement after the treatment of early stage breast cancer. Clin Oncol (R Coll Radiol). 1998;10:173-81.

17. Constant CR, Murley AH. A clinical method of functional assessment of the shoulder. Clin Orthop Relat Res. 1987;214: $160-4$.

18. Box RC, Reul-Hirche HM, Bullock-Saxton JE, Furnival CM. Shoulder movement after breast cancer surgery: results of a randomised controlled study of postoperative physiotherapy. Breast Cancer Res Treat. 2002;75:35-50.

19. Stiller J, Uhl T. Outcomes measurement of upper extremity function. Athl Ther Today. 2005;10:34-6.

20. Coster S, Poole K, Fallowfield LJ. The validation of a quality of life scale to assess the impact of arm morbidity in breast cancer patients post-operatively. Breast Cancer Res Treat. 2001;68:273-82.

21. Ware J, Jr., Kosinski M, Keller SD. A 12-item short-form health survey: construction of scales and preliminary tests of reliability and validity. Med Care. 1996;34:220-33.

22. Gartner R, Jensen M, Nielson J, Ewertz M, Kroman N, Kehlet H. Prevalence of and factors associated with persistent pain following breast cancer surgery. JAMA. 2009;302:1985-992.

23. Tasmuth T, von Smitten K, Hietanen P, Kataja M, Kalso E. Pain and other symptoms after different treatment modalities of breast cancer. Ann Oncol. 1995;6:453-9.

24. Caffo O, Amichetti M, Ferro A, Lucenti A, Valduga F, Galligioni E. Pain and quality of life after surgery for breast cancer. Breast Cancer Res Treat. 2003;80:39-48.

25. Amichetti M, Caffo O. Pain after quandrantectomy and radiotherapy for early-stage breast cancer: incidence, characteristics and influence on quality of life. Oncology. 2003;65:23-8.

26. Wouters MWJM, Jansen-Landheer MLEA, van de Velde CJH. Quality of cancer care initiative in the Netherlands. Eur J Surg Oncol. 2010;36:S3-13.

27. Kehlet H. Chronic pain after groin hernia repair. Br J Surg. 2008;95:135-6.

28. Olaya W, Wong J, Wong J, Morgan J, Kazanjian K, Lum S. When is a lymph node dissection a lymph node dissection? The number of lymph nodes resected in sentinel and axillary lymph node dissections. Ann Surg Oncol. 2013;20:627-32.

29. Alves Nogueira Fabro E, Bergmann A, do Amaral E Silva B, Padula Ribeiro AC, de Souza Abrahão K, da Costa Leite Ferreira MG, et al. Post-mastectomy pain syndrome. Breast. 2012;21: $321-5$.

30. Kehlet H, Jensen TS, Woolf CJ. Persistent postsurgical pain: risk factors and prevention. Lancet. 2006;367:1618-25.

31. Vadivelu N, Schreck M, Lopez J, Kodumudi G, Narayan D. Pain after mastectomy and breast reconstruction. Am Surg. 2008;74: 285-96.

32. Mitchell A, McCrea P, Inglis K, Porter G. A randomized, controlled trial comparing acetaminophen plus ibuprofen versus acetaminophen plus codeine plus caffeine (Tylenol 3) after outpatient breast surgery. Ann Surg Oncol. 2012;19:3792-800.

33. Gómez-Hernández J, Orozco-Alatorre AL, Domínguez-Contreras M, Oceguera-Villanueva A, Gómez-Romo S, Alvarez Villaseñor AS, et al. Preoperative dexamethasone reduces postoperative pain, nausea and vomiting following mastectomy for breast cancer. BMC Cancer. 2010;10:692.

34. VanDenKerkhof EG, Peters ML, Bruce J. Chronic pain after surgery: time for standardization? A framework to establish core risk factor and outcome domains for epidemiological studies. Clin J Pain. 2013;29:2-8.

35. Grigoras AG, Lee P, Sattar F, Shorten G. Perioperative intravenous lidocaine decreases the incidence of persistent pain after breast surgery. Clin J Pain. 2012;28:567-72.

36. Mejdahl MK, Andersen KG, Bartner R, Kroman N, Kehlet H. Persistent pain and sensory disturbances after treatment for breast cancer: six year nationwide follow-up study. BMJ. 2013;346: f1865.

37. Paul SM, Zelman DC, Smith M, Miaskowski C. Categorizing the severity of cancer pain: further exploration of the establishment of cutpoints. Pain. 2005;113:37-44.

38. Serlin RC, Mendoza TR, Nakamura Y, Edwards KR, Cleeland CS. When is cancer pain mild, moderate or severe? Grading pain severity by its interference with function. Pain. 1995;61:277-84.

39. Murrya MP, Gore DR, Gardner GM, Mollinger LA. Shoulder motion and muscle strength of normal men and women in two age groups. Clin Orthop Relat Res. 1985;192:268-73.

40. Hayes SC, Johansson K, Stout NL, Prosnitz R, Armer JM, Gabram $\mathrm{S}$, et al. Upper-body morbidity after breast cancer incidence and evidence for evaluation, prevention, and management within a prospective surveillance model of care. Cancer. 2012;118: 2237-49.

41. Mishra SI, Scherer RW, Geigle PM, Berlanstein DR, Topaloglu $\mathrm{O}$, Gotay $\mathrm{CC}$, et al. Exercise interventions on health-related quality of life for cancer survivors (review). Cochrane Database Syst Rev. 2012;8:CD007566.

42. Fleissig A, Fallowfield LJ, Langridge CI, Johnson L, Newcombe RG, Dixon JM, et al. Post-operative arm morbidity and quality of life. Results of the ALMANAC randomised trial comparing sentinel node biopsy with standard axillary treatment in the management of patients with early breast cancer. Breast Cancer Res Treat. 2006;95:279-93.

43. Hopman, MA, Harrison MB, Coo H, Friedberg E, Buchanan M, VanDenKerkhof EG. Associations between chronic disease, age and physical and mental health status. Chronic Dis Can. 2009;29:108-16. 